\title{
Developing Learning Strategies Through a Multimodal Vocabulary Project
}

\section{Steven Asquith \\ Kanda University of International Studies}

\section{Reference Data:}

Asquith, S. (2020). Developing learning strategies through a multimodal vocabulary project. In P. Clements, A. Krause, \& R. Gentry (Eds.), Teacher efficacy, learner agency. Tokyo: JALT. https://doi.org/10.37546/JALTPCP2019-44

In this research project the benefits to students of creating and using spaced-repetition vocabulary flashcards based upon different modalities-audio, visual, written, and mixed-are investigated. The study, conducted over two semesters with a class of Media English students, required students to learn the course vocabulary in stages using each modality individually before finally creating mixed-modality flashcards. At the end of the project students wrote journals to reflect on what they had learned from utilizing the different modalities to remember vocabulary and their experiences of using the technology. Subsequent analysis of these journals provides insight into not only students' attitudes towards mobile learning and using online vocabulary flashcards but also how students can become more critical in developing vocabulary learning strategies tailored to their needs

当研究では、学生が、オーデイオ、ビジュアル、文章、混合など橉々なモダリティー(手法)に基づいて、間隔反復語彙フラッジ ユカード作成及びそれを利用した勉強方法の効果について調查する。2学期にわたり実施した当研究では、メデイア英語クラ スの学生は、混合モダリテイフラシシュカードを作成する前に、それそれのモダリテイ利用して段階的にコ一ス語菓を学習す

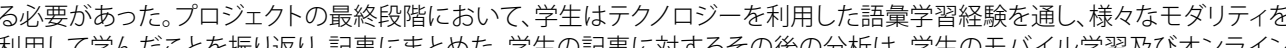

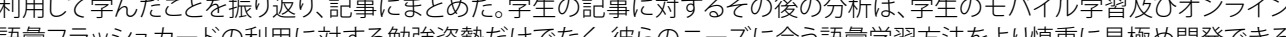

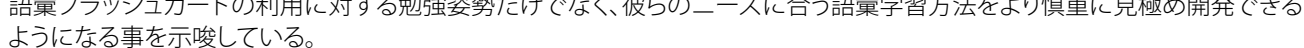

$\mathrm{n}$ recent years, as smart phones have become an increasingly ubiquitous element L of peoples' daily lives, opportunities to utilize mobile learning technologies have expanded. This is especially true in vocabulary learning, in which apps, tools, and websites such as Memrise, Quizlet, Anki, and Rosetta Stone are becoming ever more sophisticated. Now it is not only possible to create simple text-based flashcards but also to add images and audio, to share cards with different classes and groups, and to play a wide variety of review games anytime, anywhere. Despite this abundance of sophisticated learning tools however, most language learners in Japan continue to rely on wordlists provided in vocabulary books as their main method of vocabulary learning. In this research project, students were introduced to digital vocabulary flashcards. By requiring students to create, review, and reflect on flashcards using different modalities-audio, visual, written, and mixed-I invited the students to develop strategies to take better control of their vocabulary learning. Creating the capacity to take informed control of individual learning strategies is a key element of becoming an effective autonomous learner (Benson, 2001).

\section{The Institutional Context}

This project was developed at a university with a large self-access center and a focus on improving students' self-directed learning skills inside and outside the classroom. Students have access to a huge diversity of people, groups, and resources to aid them in their language learning journeys. The aim of these are not only to improve language skills, but to foster learner autonomy. In particular, the institution puts emphasis on multiliteracies and critical digital literacies to equip students for the future technologically-driven world (Cope \& Kalantzis, 2000). Supporting learners to develop skills to thrive in this environment is a key responsibility of educators at the institution. Therefore, I decided to implement a more up-to-date approach to vocabulary learning, in which learners critically evaluate and develop individual learning strategies. By creating this action research project, I could provide my students with practical skills to use in the future and investigate how vocabulary instruction might reflect the institutional ethos. 


\section{The Course}

The project was created to complement the aims of a Media English course taken by English majors in their sophomore year. This course encourages students to develop a critical view of media/the media by fostering a sophisticated understanding of modality and meaning. This is based on semiotic principles, which consider that understanding the affordances of different modes of communication is essential to using them effectively. Developing an appreciation of the features of different media and communication tools is central to the multiliteracies approach (Kalantzis \& Cope, 2012). During the course, students developed a critical understanding of media through topics such as radio/audio media, children's media, the news, and advertising. They also created media as examples of these genres, for instance, picture books, radio programs, and advertising campaigns, in which they had to understand the affordances of different communication tools to create authentic texts. The vocabulary project was designed to correspond with these units. For instance, learners studying and creating audio media used the aural mode to make flashcards. Similarly, students learning about communicating meaning through visual representations created flashcards using images. By designing the project to correspond with the media course content in this way, my hope was that learners would not only learn new vocabulary but also deepen their understanding of multimodal communication.

\section{The Rationale}

In my personal experience of studying Japanese, I discovered that spaced-repetition digital flashcards were a powerful tool to efficiently expand my vocabulary. In particular, the ability to access and review the sets "mobily" meant that I could organize my time effectively. For instance, short breaks at school or on the train became opportunities to study, and after a period, this behavior became habitual. This ability to more effectively organize and utilize my time was cultivated due to the nature of the Anki spaced-repetition software, which made it easy for me to track my progress. I also found practicing the cards to be fun and rewarding. Because of this experience, I was curious about the potential of using digital images and audio to improve such direct learning methods. Therefore, I decided to design a project to share the affordances of digital flashcards with my students through integrating the technology with the Media English curriculum.

Research on the use of digital flashcards echoed the benefits I experienced and provided a few further considerations. In recent years, it has become widely accepted that deliberate learning of vocabulary using flashcards is an effective way of learning words (Elgort, 2011; Nakata, 2011), especially when used in support of other methods
(Nation, 2013). Spaced-repetition, in particular, has been shown in a number of studies to be an effective means of retaining word meanings long-term (Bloom \& Shuell, 1981; Kornell, 2009), and digital tools, such as Anki used in this study, deliver this strategy "mobily." Hanson \& Brown (2019), who investigated spaced-repetition using Anki, found it to be effective but time-consuming, with learners who were not intrinsically motivated to study often unwilling to use it. They suggested that tools with more games and options were more likely to be effective with their participant group. They chose Anki primarily because its simplicity made it an effective way of testing spaced-repetition experimentally. Nation (2013) stated that flashcards provide a way of "quickly increasing vocabulary size through focussed intentional learning" and gave the following advice about creating cards: "1.) Put the word on one side and the meaning on the other to encourage retrieval. 2.) Use L1 translations. 3.) Use pictures where possible. 4.) Keep the cards simple" (pp. 445-446). He also pointed out the utility of pictures, especially using mnemonics, for learning words that are tricky to remember. These days images can be found and/or created quickly and easily using search engines, editing apps, and mobile phone cameras. Similarly, audio, such as vocabulary items captured in context, could provide valuable learning opportunities if added to flashcards. As students now exhibit "a high level of mastery" in using their smartphones as tools for language learning (Wrigglesworth \& Harvor, 2018, p. 445), understanding how these technological affordances might be more effectively harnessed is relevant to students, teachers, and researchers alike.

In addition to introducing students to the potential of spaced-repetition digital flashcards, my goal was also to encourage them to develop skills to become more selfdirected vocabulary learners in the future. Nation (2013), on autonomous learning of vocabulary, stated that "the more learners are aware of how learning is best carried out, the better the learning is likely to be" (p. 583). This awareness could encompass understanding what is involved in knowing a word and how to find this information, how to track and manage progress, how to organize time, and how to find strategies to suit them. By including a self-reflective and analytic element into the project, I hoped that students would become more metacognitively aware of strategies that were effective for their individual learning styles. Helping students to become active and discerning agents in their vocabulary study was a key aim.

The Project

This project was designed to introduce students to mobile vocabulary learning using multimodal flashcards and to have them reflect upon and develop strategies for their use. 
This was achieved by having students create and use spaced-repetition flashcards on the Anki flashcard program and website over the course of two semesters. The vocabulary was a list of approximately 120 words or phrases taken from the Media English units. The project was divided into four 7-week stages, corresponding to the types of flashcards created and used. In each stage, students made and reviewed approximately 30 flashcards with the word written in English on one side of the card and only the specified modality used on the reverse. Therefore, in the first stage, only audio cues were used on the reverse side; in the second stage, only visual cues; in the third stage, only written cues;and finally in the last stage mixed modality cues. Students were encouraged to be creative in their flashcard design and the types of media they used. For instance, in the audio stage students could record either the definition in English or a translation in their L1, record themselves using the word in context in either an original or dictionary example, or record an authentic usage of the word from another media source; in the visual stage they might include an image from Google image search, a word cloud or mnemonic, a photo of a self-drawn image of the word, or even a photo of the word being used in a context. Students could use as many cues as they wanted as long as they were in the specified modality, so a student might include an audio translation of a word and it being said in context on the same card. The project was designed in this way to deepen the students' knowledge of effective flashcard creation during each stage and to help them appreciate different aspects of words and word knowledge. In the final stage, students combined what they had learned to make effective mixed modality flashcards. The project was conducted over an extended period, two semesters, so that students had enough time to analyze, reflect upon, and improve their individual learning strategies.

The main research instrument was the Anki spaced-repetition flashcard program and associated website. Although there are a number of excellent vocabulary flashcard programs and apps on the market (Quizlet, Memrise, Tiny Cards, etc), Anki was chosen because at the time of selection it most successfully met the following criteria:

1. It utilized spaced-repetition. This was deemed essential as research has shown that this is a highly effective method of deliberate vocabulary learning using flashcards (Bloom \& Shuell, 1981; Kornell, 2009).

2. It was possible to select and add audio files and images found from web browsers as well as uploaded directly.

3. It was free.

The spaced-repetition Anki flashcard program consists of a computer program on which multimodal flashcards can be created using a computer and a website where these flashcards can be accessed from any device. Although it is possible to create multimodal flashcards using the Anki app, this was not available on the iPad for free. One major drawback of using the Anki program was that flashcards needed to be input using a specific computer and the card sets could not be easily transferred. Therefore, flashcards had to be created during class time using the institute's computers rather than independently as homework. Student's lack of familiarity with these Mac computers was at times problematic. It was also difficult and time consuming to add personalized content of files recorded on student iPads as this required the use of Google Drive or similar cloud-based technology. As students were experts at creating digital content using their iPads (they do this in most courses), this is likely to have significantly restricted their creativity.

\section{Data Collection}

The project was cleared with the university's institutional review board and conducted with 18 students, who provided informed consent. In order to understand students' perceptions of learning vocabulary this way I collected semistructured journals from each student at the end of the project. These logs included questions about students' experiences of making and reviewing the cards; a set of seven open-ended prompts such as "A good flashcard is ...," "It was difficult to...," and "I learned ...."; a reflection on what each student had learned; and a comment about each student's study plans for the future. The reflective log sheet is included as Appendix A. Logs were analyzed qualitatively to discover themes that emerged from the data. These were then coded into nine main themes and 59 subthemes. As these codes were based on the structured format of the logs, they are guided. However, students provided a wide range of reflections. A space was also provided for any other comments. To encourage honest feedback, students were reassured that the grading of reflections was based on the amount and quality of comments, not whether these were positive or negative. This was communicated to students both verbally and in writing in their L1.

\section{The Project Goals}

The research project was designed based on the following goals: (a) to encourage students to think more critically about their vocabulary study, (b) to introduce students to the benefits of mobile vocabulary learning tools, (c) to provide students with a better understanding of the affordances of different modalities, and (d) to enhance students' self-directed learning strategies. The students' self-reflection journals were collected, analyzed, and coded to reveal the extent to which these outcomes were achieved. 


\section{The Outcomes}

The data emerged from the students' reflective logs conducted at the end of the project. Student comments were coded into nine main themes and 59 subthemes. The number of comments coded as each subtheme is provided in parentheses in each data table. Subthemes that occurred as single comments are listed in Appendix B. Each of the main themes is explained in greater detail in the section following each table. Although many of the reflections included insights corroborated by vocabulary research findings, these were deduced by students independently.

Table 1. Student Comments About Modalities

\begin{tabular}{ll}
\hline Cue modality (total*) & Comment (times made) \\
\hline Visual (29) & Cards are fun to make. (7) \\
& Are effective (6) \\
& Cards are fun to review. (5)
\end{tabular}

Good for words that are difficult to remember or understand (3)

Are good for nouns and adjectives (2)

Are good for words with clear meanings (2)

Some words are difficult to express using pictures (2)

I used as many pictures as possible (2)

Audio (10)

Good for words with difficult pronunciation (5)

Inconvenient (3)

Written (18)

Used the most (5)

Used translations (5)

Best method (4)

Good for adding different word knowledge, example sentence, antonyms etc (2)
The modality on which students commented the most was visual (see Table 1). In line with research findings (see Nation, 2013), students felt that flashcards using images were more effective and fun to make and review. However, in the general comments category six students stated that making flashcards was difficult. Searching for and adding images to the cards on unfamiliar MacBook computers was certainly a factor in this, and if the project were repeated, it would be preferable to use a more streamlined iPad-based application such as Tiny Cards. Furthermore, students suggested that adding images to all flashcards is not the most effective approach and that it is better to select images for words with clear meanings that can be expressed through pictures, such as nouns and adjectives. For other, more abstract words, different methods would be preferable. Also, three students suggested that it would be good to use images only with words that are difficult to remember or understand. Making personalized flashcards, rather than simply using ready-made sets, encouraged students to think more critically about the task.

The modality that was least popular was audio cues. Students felt that these were inconvenient to use, especially as they required headphones to practice in public places such as on the train. This echoes Stockwell and Hubbard (2013), who emphasized the importance of matching the affordances of a mobile learning tool to its context of use. In general, students preferred to use written definitions and examples rather than audio However, the utility of these cards was not dismissed completely, and five students suggested that audio should be included in flashcard design when a word has difficult pronunciation.

Written cues were often seen by students as the most important element of a flashcard, after which other modalities might be added. Many students felt that this was the best method and the cue that they used the most. It was also useful to include different aspects of word knowledge. However, although this modality provided the opportunity to include a lot of information-such as example sentences, definitions, collocations, synonyms, and antonyms - many students realized that it was important to be selective in their design choices. Adding lots of detail to the cards is time consuming in both the creation and review stages. This echoes research findings that the best vocabulary flashcards are simple (Nation, 2013). Understanding how to spend time efficiently is a key element of using flashcards.

*Totals include single-instance comments listed in Appendix B. 
Table 2: Student Comments About Designing the Flashcards

\begin{tabular}{ll}
\hline General idea (total*) & Comment (times made) \\
Effective flashcard & The best flashcard design is dependent upon the characteristics \\
of each word (4) & It is important to choose what we want to learn (focused) (4) \\
& I can increase my depth of knowledge of known words by \\
& including different information (4) \\
& Personalizing the cards was motivational (3) \\
& It was fun to personalize the cards (3) \\
& Simple and easy to understand (3) \\
& Personalizing the cards was more effective to remember the \\
& words (3) \\
& It is better to include more information (2) \\
& We should focus on our weak points (2) \\
& We should adapt the method depending on our goals (2) \\
& Using different modalities was effective (2) \\
& Images/words/... are better for me (3) \\
& I could discover my learning preferences (2) \\
& I could understand one of my weaknesses (2) \\
Repetition is important (2)
\end{tabular}

*Totals include single-instance comments listed in Appendix B.

Thirty comments were made by students related to designing the flashcards. Many of these comments were relevant as they showed that students were making critical choices based upon analysis of the task and their needs. Developing such learner agency is a key component of self-directed learning skills. The comments centered on three main ideas: (a) being selective, (b) personalization, and (c) learning styles (see Table 2). First, students became aware of the importance of tailoring the flashcard design to their needs and the features of the word. Students reported that each individual word has a best flashcard design based upon its features. For instance, the verb portray may be best shown in a written contextual form such as Daniel Radcliffe portrays Harry Potter in the movies, whereas adjectives such as elegant or corny are far more effectively represented visually. Students also said that choosing what to learn about words depended upon their needs relating to that word. For instance, four students commented that they could increase their knowledge of already partially known words, an important and often neglected feature of vocabulary study (Nation, 2013). Other students suggested that they should focus on their individual goals and design flashcards based on what they want to learn. Learners also recognized that simplicity in the design of the cards was important. Personalization was also deemed to be important. This was often done by adding an image, which students felt made the cards more fun to review. Decisions about word knowledge to include were often based on students' perceptions of what they needed to know. Personalizing the flashcards was seen as motivational, especially when reviewing the cards. By creating personalized cards students could engage with the words on a deeper level at both the creation and review stages of learning. Finally, 10 comments were made by students that the project helped them to discover a particular effective strategy or personal learning preference. Learners deduced these insights by themselves through engaging in the project. By creating opportunities for students to develop skills independently and experientially, students can become more autonomous.

Table 3. Comments About the Technology

\begin{tabular}{ll}
\hline Topic (total $\left.{ }^{*}\right)$ & Comment (times made) \\
\hline The technology (37) & Can use time more efficiently (9) \\
& Can study in many places (5) \\
& Reviewing was fun (5) \\
& Making flashcards was a problem because of the Macs or the \\
& program (5) \\
& Mobile learning was the best part of this project (4) \\
& It is portable (not heavy books) (3) \\
& Can develop a routine (2) \\
& Spaced-repetition was very effective (2) \\
\hline
\end{tabular}

*Totals include single-instance comments listed in Appendix B.

The overwhelming majority of students who took part in this project felt that mobile learning was effective and useful (see Table 3). Students stated that this was a convenient, efficient, and fun method of studying vocabulary. Several students wrote about being 
able to develop a routine and practice words conveniently, without having to carry around heavy vocabulary books. Also, learners felt that spaced-repetition was very effective. However, making the cards on the unfamiliar Mac computers was difficult. It was also interesting that one student stated that they get distracted by other apps. This seems like a key limitation of many mobile technology tools upon which notifications and messages appear automatically. Although mobile learning is clearly very convenient, environmental and online distractions can be an obstacle to concentration.

Table 4. General Comments About the Past and Future

\begin{tabular}{ll}
\hline Topic (total*) & Comment (times made) \\
\hline Past (5) & Only wrote the words or used a vocabulary book previously (5) \\
Future (29) & I will use a different vocabulary application (8) \\
& I will not continue Anki (5) \\
& I will continue Anki (5) \\
& Can use for specific purposes TOEFL, TOEIC, French (5) \\
& I want to use the words (3) \\
& I will return to a previous method, such as using a vocabulary \\
& book (3) \\
& Making the cards is hard (6) \\
General comments & There were not enough words to remember (2) \\
(8) &
\end{tabular}

*Totals include single-instance comments listed in Appendix B.

For most students of English in Japan, the main method of learning vocabulary is rote memorization of vocabulary lists from books. Therefore, using a device to learn vocabulary digitally was a new experience for many. In comments, the majority of students stated that they wished to continue using a digital system with only three preferring to return to a previous method, such as using vocabulary books (see Table 4). However, many students said that they would prefer to use a different tool. This was probably partly a consequence of having to create the flashcards on the computer program, when using an iPad app would have been more user friendly. Because students are familiar with many different editing and recording apps, it would have been advantageous if they could have embedded these in cards easily. However, at the time of planning the project I was unaware of an iPad tool with the necessary features. Finally, it was rewarding to see that some students appreciated the applicability of this project for their broader studies in other disciplines.

\section{Conclusion}

Through this project I aimed to encourage students to be more systematic in their vocabulary study using a mobile learning tool. This was also intended to improve students' understanding of the affordances of different modalities and to enhance their self-directed learning strategies. Student comments suggested that not only did they develop an understanding of the affordances and limitations of mobile technology and different modalities, but also that this understanding was sophisticated and personalized to meet their needs. Many students realized that words, modalities, and learning tools have specific features, and by using these in a critical and integrated way they could develop effective vocabulary learning strategies. This is more complex than simply adding lots of information to flashcards, as time spent is a key factor. Only by analyzing their individual needs and learning preferences could students craft flashcards that were highly effective. Matching individual needs to the affordances of the learning tools available and the features of what is to be learned is at the heart of effective autonomous learning. As such, it was gratifying to see learners become aware of this concept.

If I were able to conduct this project again using a more user-friendly application on students' iPads and/or smartphones, then I feel confident that students would make far more creative use of cameras, voice recorders, and editing software to produce effective multimodal flashcards. Such learning could be further enhanced by employing peer-topeer collaboration in the creation of individual flashcards and sets. In the future as digital flashcard programs progress and become more sophisticated, it is likely that most will use spaced-repetition, provide options to use different embedded media, and be more closely attached to dictionaries and useful word lists. However, these improvements are only of limited value if they do not match learners' needs, environment, motivations, and learning preferences. How learners can be trained to be more active and sophisticated agents when using these tools is an important area of research. Only through training learners to critically evaluate the affordances of such new technologies, based upon their individual circumstances, can these tools be utilized to their full potential. 


\section{Bio Data}

Steven Asquith is a senior lecturer at Kanda University of International Studies and coeditor of JALT's The Language Teacher, My Share column. His interests include learner autonomy and vocabulary, digital pedagogies, and new learning design.

\section{References}

Benson, P. (2001). Autonomy in language learning. London, England: Pearson.

Bloom, K. C., \& Shuell, T. J. (1981). Effects of massed and distributed practice on the learning and retention of second-language vocabulary. Journal of Educational Research, 74(4), 245-248. https://doi.org/10.1080/00220671.1981.10885317

Cope, B., \& Kalantzis, M. (Eds). (2000). Multiliteracies: Literacy learning and the design of social futures. London, England: Routledge.

Elgort, I. (2011). Deliberate learning and vocabulary acquisition in a second language. Language Learning, 61(2), 367-413. https://doi.org/10.1111/j.1467-9922.2010.00613.x

Kalantzis, M., \& Cope, B. (2012). Literacies. Port Melbourne, Australia: Cambridge University Press. Kornell, N. (2009). Optimising learning using flashcards: Spacing is more effective than cramming. Applied Cognitive Psychology, 23(9), 1297-1317. https://doi.org/10.1002/acp.1537

Nakata, T. (2011). Computer-assisted second language learning in a paired-associate paradigm: A critical investigation of flashcard software. Computer Assisted Language Learning, 24, 17-38. https://doi.org/10.1080/09588221.2010.520675

Nation, I. S. P. (2013). Learning vocabulary in another language (2nd ed.). https://doi.org/10.1017/ СBO9781139858656

Hanson, S. A. E., \& Brown, C. M. (2019) Enhancing L2 learning through a mobile assisted spacedrepetition tool: An effective but bitter pill? Computer Assisted Language Learning, 33(1-2), 133155. https://doi.org/10.1080/09588221.2018.1552975

Stockwell, G., \& Hubbard, P. (2013). Some emerging principles for mobile-assisted language learning. Monterey, CA: The International Research Foundation for English Language Education. Retrieved from http://www.tirfonline.org/english-in-the-workforce/mobile-assistedlanguage-learning

Wrigglesworth, J., \& Harvor, F. (2018). Making their own landscape: Smartphones and student designed language learning environments. Computer Assisted Language Learning, 31(4), 437-458. https://doi.org/10.1080/09588221.2017.1412986

\section{Appendix A \\ The Student Reflection Log}

Anki Vocabulary Project Log

As part of this project you must keep a log of your experiences. Please write as much as you can about the following topics. These logs will be part of your final grading.

\section{Please describe your experience of the following topics:}

1. Making the audio/visual/written flashcards using the Anki program.

2. Reviewing the cards

\section{Complete the following sentences:}

1. A good flashcard...

2. Making each flashcard took about ... minutes.

3. It was fun to ...

4. It was difficult to ...

5. I learned ...

6. Next time I want to ...

7. The best part of learning vocabulary this way was ...

\section{Reflection}

Please write 150 words explaining what you learned about studying vocabulary from this project as a whole.

Will you use Anki or a similar program to continue studying vocabulary in the future? Do you have any other comments? 


\section{Appendix B}

Single-Instance Comments

\begin{tabular}{ll}
\hline Topic & Comment \\
\hline Visual cues & Are good for getting a rough meaning \\
& Easy to make \\
Audio cues & Didn't use these often \\
& Good for completely unknown words \\
Written cues & Good for difficult spellings \\
& Boring \\
Effective flashcard & By learning words more deeply we can connect them better to \\
other words & I can increase my depth of knowledge of known words by \\
& including different information \\
& $\begin{array}{l}\text { The best type of flashcard depends on what is already known } \\
\text { about a word } \\
\text { I used more information than previously and could learn in } \\
\text { greater depth } \\
\text { Cards need context }\end{array}$ \\
Personal learning & \\
styles & I get distracted by other apps \\
The technology & Can make the flashcards more easily now
\end{tabular}

